\title{
Advanced Food Products Prepared through Academic and Industry Collaboration
}

Dimitris Skalkos

The University of The Aegean, Department of Food Science \& Nutrition, 2 Mitropoliti Ioakim str., Myrina, Lemnos, Greece

\begin{abstract}
New product development (NPD)is vital to the food industry because: 1 ) customer's needs and wants are constantly changing, 2) trade customers want new products, 3) technical developments, 4) legislation, 5) competition, and 6) shortened product life-cycles. As NPD can be a time and resource consuming process companies and research centers are constantly investigating for structured processes which will enable cost - effective and timely product launches. A new, innovative open innovation (OI) model of collaboration process between university and industry focusing on food new product development (NPD) has been developed and implemented successfully over the last 8 years. In 2011, in view of the student's eco-food competition "ecotrophelia" initiated in Greece by the Federation of Hellenic Food Industries (SEVT), we developed an and launched a campaign in order to recruit Greek food companies and develop together novel foods for the competition. The initiative was successful and productive thus is continued annually ever since. Overall, 18 innovative foods have been developed and produced at the pilot phase by 18 groups of students of the Department of Food Science and Nutrition (University of The Aegean), in collaboration with 10 Greek food companies.
\end{abstract}

Keywords: Open innovation, New product Development, Academic-industry collaboration

\section{Introduction}

Innovation is an important tool for companies to adjust to competition and changes in the market [1], and the importance of innovation is justified [2], by the action of conjoined and critical forces such as intense international competition, market sophistication and quick technological changes. In this way, although the competitive advantages can be related to certain factors such as company size and larger resources, there is a growing predominance of companies flexible enough to bring together knowledge and technological capabilities to develop new products. Product development process is defined [3] as "the entire set of activities required to bring a new concept to a state of "market readiness". Ulrich and Eppinger [4] mention that "product development is the set of activities beginning with the perception of a market opportunity and ending in the production, sale, and delivery of a product". Clark and Wheelwright [5] also interpret new product development as a process in which an organization transforms market opportunities and technical possibilities into the manufacturing of a commercial product. The adoption of a project methodology is essential, since it helps the designers to rely on a trustworthy model for their work accomplishment and, despite the developer's desire to design for customers (meeting demanded attributes such as appearance, design, durability, etc.), there must also be a concern to design for the manufacturer (simple manufacture, usage of few resources, etc.), for the sales team (easy transport and stocking, etc.), among others [6].

Large enterprises have advantages such as renowned brands, earnings in scale of massproduction and an influence on contract development both with customers and suppliers. 


\section{Dimitris Skalkos \\ Advanced Food Products Prepared through Academic and Industry Collaboration}

However, for the development of products and technologies ancillary to the core business, large firms tend to deploy the assistance of universities. In the US, firms, tend to use the help of universities in products in the pre-competitive stage. This practice is important for protecting the intellectual assets associated with the product and technology. Large firms often use universities as a forum for exploring ideas not only with the faculty and students, but also with others in the industry. In this respect, universities help develop social capital for the industry that facilitates technology transfer and innovation [7].

Comparatively to large companies, SMEs tend to present greater flexibility, for they can mobilize themselves to meet market demands in a shorter time than large companies [8]. SMEs face difficulties in aggregating innovations, especially product innovations. Acquiring knowledge and skills through external collaboration has become for SMEs an effective and efficient way towards the success of innovations. Small firms interact with universities for the development of technology related to their core and ancillary business areas. Small firms generally lack adequate resources and so try to make the best utilization of any available resources.

Universities differ in terms of their capabilities and strategies [9]. Large universities with a national reputation of high calibre, such as MIT, Carnegie Mellon or Stanford, can be better suited to add to the social capital of the industry. Smaller and less known universities become more suited as problem solvers. The cultural difference between universities and firms is an important issue that generates obstacles in their collaborative efforts. The development of products requires a tight control and monitor which is a process that the universities are not familiar with. Universities are potentially great resources for corporations for developing new technology and products. In recent years, there have been more reasons for these two types of organizations to collaborate for mutual benefit. In a dynamic global economy, this has become critically important, as evidenced by the experience in Finland. Contract research, by a research center or a professor, is often a vehicle for collaboration between a university and a firm. In Finland, TEKES, the Finnish Technology Development Agency, promotes the industrial collaboration by requiring that all of its projects and products be collaborative. The policy implemented by TEKES not only promotes interaction between a firm and a university but also decentralises the control and monitoring of the projects and the products developed.

\section{Literature Review and Research Focus}

Innovation is the application of ideas, technology and processes in new ways to gain a competitive advantage and create value. It plays a vital role in all facets of modern life [10]. Innovations can become commodities at an unprecedented speed, and consequently, continuous effort is required. The mantra "innovate or die" is no longer sufficient. Open innovation (OI) and innovation partnerships could be the leitmotif for today's companies. OI is defined as "a paradigm that assumes firms can and should use external ideas as well as internal ideas, and internal and external paths to market, as the firms look to advance their technology" [11].

OI has seen a massive expansion in recent years [12]. The goal sets back in 2000 by Proctor \& Gamble for their OI model of "Connect + Develop"-that 50\% of innovation acquired from outside the company-has made significant inroads [13]. OI has spread and mushroomed in many industries (e.g. pharmaceuticals, chemicals, biotechnology, drugs, software), and the large food industry has followed too $[10,14]$. Despite OI's widespread applications, small and medium-size enterprises (SMEs) and others operating in traditional sectors are struggling with its implementation due to their relatively low level of absorptive capacity, and management challenges which are perceived as unattainable [15]. The untapped potential and full adaptation of OI is particularly relevant for the EU Food and Drink (F\&D)-the EU's largest manufacturing sector, which employs some 4.4 million people generating $14 \%$ of the total manufacturing jobs. The SMEs are especially struggling with OI implementation $[16,17]$, and although they comprise $99.1 \%$ of the 310,000 companies, they generate only $49 \%$ of the F\&D turnover. This topic has attracted much attention and is under deliberation by various EU bodies [10]. Collaboration is 


\section{Dimitris Skalkos \\ Advanced Food Products Prepared through Academic and Industry Collaboration}

a piston of the OI, in the engine that drives economic growth and new product development. Value creation is the ultimate goal of any partnership: without it, the concept holds no real merit for the partners. Despite the great potential, significant inroads still need to be made in the collaboration between industry and academia to develop an OI value creation partnership. . Academia's long history of working in isolation, its different value chains and a general misunderstanding between parties furnish a partial explanation for their "staying at arm's length." So-called ethical conflicts threaten academia by distracting it from teaching and basic research, undermining collegiality, encouraging secrecy, preventing or delaying publication, and devaluing the human component [18]. Traditional collaborative conflicts between academia and industry include confidentiality, publishing, IP rights and ownership. The mindsets and research foci of the two institutions are also quite different: while the university focuses on fundamental research $(R)$, industry works primarily on development (D), with a typical ratio of $D$ to $R$ in the food industry exceeding 4:1. Concerns about potential conflicts of interest arise when members of the academic community interact with industry (e.g., consultants, scientific advisors). These concerns are alarming, but collaboration principles should serve as a platform for promoting the development of mutually beneficial relationships. Other factors, such as culture and funding, have also been identified as significant constraints stifling fruitful collaboration.

Another difference between academia and industry is their value chain. While the industry is driven mainly by its bottom line and gaining full IP rights, academia is primarily motivated by the pursuit of basic science and knowledge dissemination, student education, publications and often also full IP rights. OI proliferation has proven that academic freedom is not affected, and that company-sponsored research is quite rare. It is generally accepted, especially by EU countries, that university innovations have an underutilized and unrealized potential that continues to lie dormant. Consequently, sustained efforts to advance university innovations are needed. Building bridges between university researchers and businesses is critical for knowledge transfer-this is no longer an option, but a must, and collaboration can pave the way. However, even OI focuses on quite narrowly defined, short-term transactions. The latter miss the opportunity to build much longer, trust-based relationships that can engage diverse teams in tackling more diffuse and broadly framed challenges [19]. This issue may be because OI has only recently seen broad utilization and it should continue to target a larger scope for driving collaborations between academia and industry.

Toward implementing significant changes in academia-industry collaborations and the pursuit of innovation, collaborative principles should be expanded and an overarching vision should be developed. This game-changing vision should be based on new shaping strategies (i.e., reshaping broader markets, industries, or social arenas [19]) which will be expanded to include academia as well. The new vision and shaping strategies should address the broad scope of innovation, including product innovation and furnish industry and academia with opportunities to seek improved means and tools to develop platforms, and new products that will maximize mutual efforts, enable participation, promote learning and societal responsibility, and lead to the creation of an innovation ecosystem. Academia should play a paramount proactive role in the conceptualization, deliberations and design of this new vision, and should contribute to its content leading to innovation and new product development for the mutual benefit of the academic and business sector.

\section{Research Methodology}

The road from a discovery stemming from basic research to a commercial product, process or service is long and rife with significant obstacles. Typically, a funding gap or "valley of death" (VoD) exists between basic research and commercialization [20]. To simplify the concept of VoD, the innovation sequence can be typically depicted in three stages: stage 1 is basic research, also termed pre new-product development (NPD), providing what is known as the "front end" (or "fuzzy front end") of innovation; stage 2 includes the transformation from research outcome into a potentially marketable product/service; stage 3 is commercialization and diffusion of a new product/service, translating projects into economic value. 


\section{Dimitris Skalkos \\ Advanced Food Products Prepared through Academic and Industry Collaboration}

In this paper, we have developed an OI model of collaboration between Greek food SMEs and the Food Science \& Nutrition Department, University of The Aegean, Greece, fulfilling the first two of the above mentioned three innovation sequence stages leading to food NPD. The OI partnership described here consists of three main groups of people: students, academic staff, and industry personnel. Managing the relationships between the three partners (students, academic staff, and industry representatives) is vital to a successful collaboration and end product outcome. The team members of the OI program are structured into three types of members: core, extended and ad hoc teams (Table 1).

Table 1: Team Members for Open Innovation and NPD

\begin{tabular}{|c|c|c|}
\hline Team & $\begin{array}{c}\text { Function and Frequency } \\
\text { Of meetings }\end{array}$ & Members \\
\hline Core & $\begin{array}{c}\text { Meet frequently (weekly) to } \\
\text { discuss and guide students, } \\
\text { review their work } \\
\text { and design weekly plans }\end{array}$ & $\begin{array}{c}\text { Students (Food Science and Nutrition } \\
\text { undergraduates) } \\
\text { Academic staff (supervisor) }\end{array}$ \\
\hline Extended & $\begin{array}{c}\text { Meet monthly and at the four } \\
\text { scheduled } \\
\text { review meetings, to monitor progress } \\
\text { and give feedback }\end{array}$ & Company's representatives \\
\hline Ad hoc & $\begin{array}{r}\text { Invited when required during the } \\
\text { project }\end{array}$ & $\begin{array}{c}\text { Academic course coordinator } \\
\text { External experts }\end{array}$ \\
\hline
\end{tabular}

The core team includes the students and their supervisor (i.e. academic staff from the Department of Food Science \& Nutrition). The extended team members include a representative from the client food company (usually a project manager, design engineer, or the managing director of the small company himself) and other company's practitioners with an engineering or a business development background. The ad hoc team members include the academic course coordinator (the person who has practically developed, and managed throughout the years the overall project) and other specialists and external experts who may be contacted whenever it is required during the development of the process. This structure does not have to be rigid and is flexible fulfilling the needs and requirements of each project every time. It is efficient however, based on the successful outcome with pilot NPD all these years. The core team meets more often and is more heavily involved than the other sets of members.

The question of how best to make the OI collaboration work successfully between university and industry is addressed here. The framework described here represents an OI partnership in product development between the University of The Aegean and food industry partners (Figure 1).

It consists of 5 stages implemented within a nine months period from October to June. The management (university mainly) / client (food SME mainly) role, the expected outputs, and the time table for each stage are shown in Figure 1. Through this overall process, the students (as a group for each project) are participating in the student "ecotrophelia" competition for new innovative food products. This is a European competition organized in Greece by the Federation of Hellenic Food Industries (SEVT). The final event takes place in June every year where the students present their pilot produced products, and the best products are awarded (end of the project).

Companies are aware of project time constraints due to students undertaking other courses at the university, but occasionally business pressures demand a quick response. Students are made aware of these real-world pressures of time and have risen to these challenges very well, 


\section{Dimitris Skalkos \\ Advanced Food Products Prepared through Academic and Industry Collaboration}

and it has been to their advantage. It is mutually beneficial when all three parties meet at critical times during the process, as per the framework schedule's review milestones. The companies set aside these dates and times so that they can take place in the progress and direction of the project.

A holistic, multidisciplinary approach to the process of product development allows for a range of perspectives to be explored, concurrently whenever possible. It allows for client reviews and input at stages, checking that milestones have been reached as specified and that the schedule is on target. This framework gives clients confidence that they can see the direction in which a project is heading at key points during development, and can provide input or steer it in a way that suits their objectives.

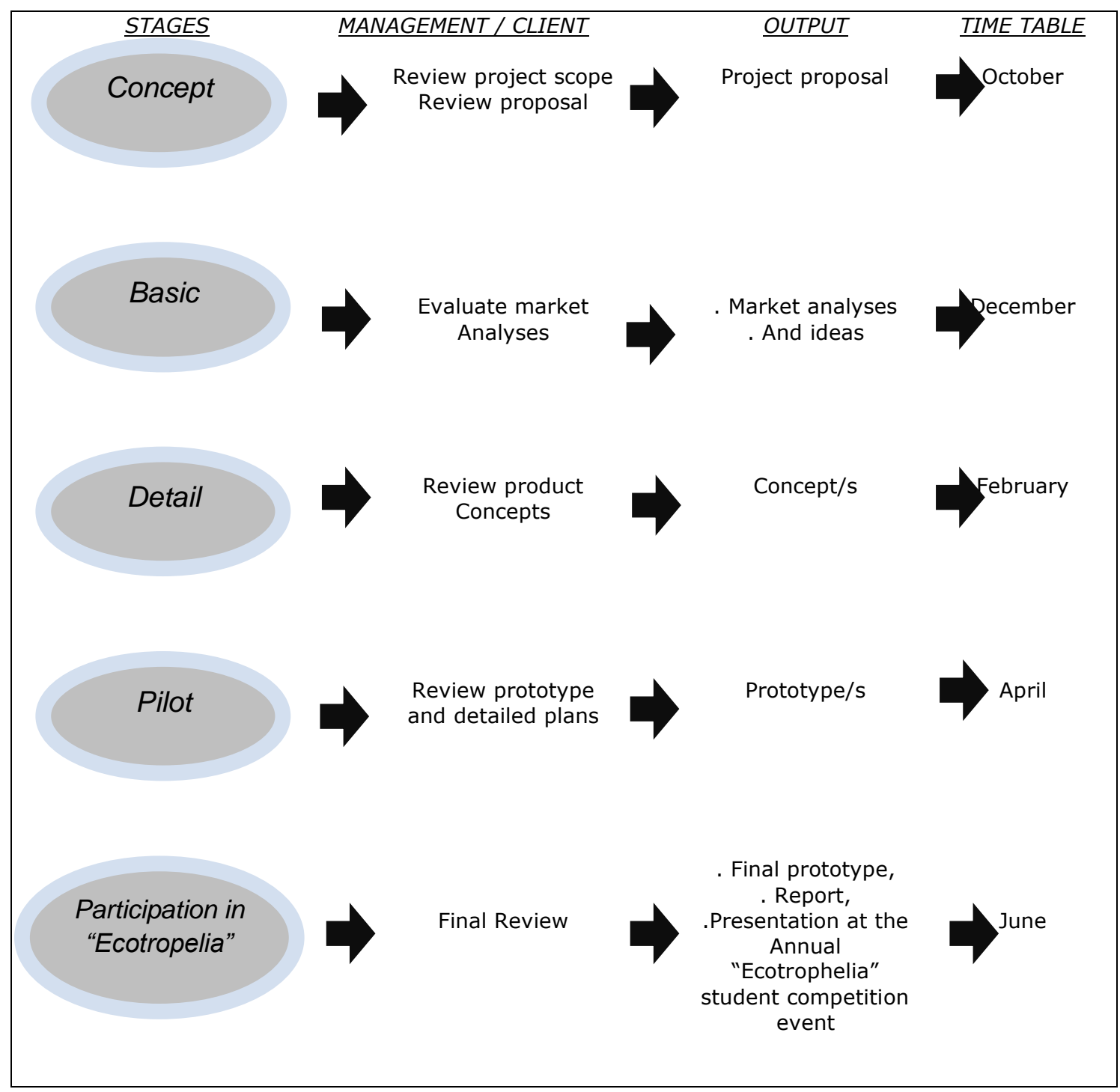

Figure 1: Product Development process

\section{Results}

The validity of the proposed OI academic - food industry model is based on its successful implementation over the last eight years, since 2011. Over these years 18 new, innovative food products have been developed by the undergraduate students of the Food Science and Nutrition department, in collaboration with 10 Greek food SMEs, produced in the pilot phase, and presented at the Ecotrophelia competition. The products per year were 1 (in 2011), 3 (in 2012), 


\section{Dimitris Skalkos \\ Advanced Food Products Prepared through Academic and Industry Collaboration}

5 (in 2013), 3 (in 2014), 3 (in 2015), and 3 (in 2016). Three products per year seem to be the optimum number that the current capacity of the OI university - industry's model can successfully manage, which includes the participation of 12 students (4 students per project). The ten companies which have participated so far in the process are: APIVITA S.A. (4 times), MEDITTERA S.A. (3 times), GIOTIS S.A. (3 times), UNISMACK (2 times), OLYMPOS (1 time), PELOPAC (1 time), PAYLIDIS (1 time), CHIPITA (1 time), STERGIOY (1 time), XRYSAFIS (1 time). The fact that most companies have participated more than once proves that the model is very useful for the food industry. It is an excellent brain storming process which strengthens the company's innovation capacity, dynamism, and the ability for new product development regarding its size and sub-sector of activity. Each year one of the produced products receives an award among the participating products in the ecotrophelia competition (more than 15 products participate annually). This result proves the quality of the produced products, and the liability of the applied OI model. This year, three more products are at the developing stage, in collaboration with three SMEs, and will be presented at the ecotrophelia completion 2017 this June.

The selection of suitable products projects was critical to successful project outcomes. It is vitally important that the project has the potential to meet the university's requirements, the requirements of the industry partner, the capabilities of the students, and the requirements of the ecotrophelia competition. The university's / competition's requirements were made clear to industry partner each time in terms of time duration (of nine months), the complexity level of the project selected, and students' skills, knowledge, and capacity. Projects have been selected based on the following:

- A good fit with the students' knowledge and skill levels

- A fit with the timeline, allowing the opportunity to go through all of the major stages of development

- The scope of the project must be sufficiently wide to allow student creativity, and at the same time focused on a clear customers' nutritional need

- A clear definition of company requirements, expectations, and innovation strategy

- Opportunity for stakeholder input and application to design

- Sufficient opportunity to consider commercialization options as part of the project - including economic, marketing, and manufacturing plans

The type of the 18 products covers a variety of different kinds of foods from bakery to snacks, from soft drinks to milk, and from olives to sweets. All of them exhibit nutrition characteristics based on their specific healthy ingredients (most of them of Greek, local origin). At the same time, these products combined excellent organoleptic properties, attractive, innovative packaging and appealing English names. The Greek originality of the main ingredients used for each product promoted them as unique Greek "traditional style" foods part of the existing traditional Mediterranean diet. Finally, the economics of each product calculated in details from the cost of raw materials, of production, marketing and distribution, including margin profit provided competitive retail prices compared with the rest of the antagonistic products in the market to be able to enter the market with advantages. Microbiology tests, expiration dates estimations, HACCP production processes requirements, and an overall business plan are among the accumulated data for each product gathered and presented to the ecotrophelia experts' panel who conducted the competition and decided the awards each year.

\section{Conclusions}

The industry can benefit from collaborating with universities in Open Innovation, and small and medium enterprises that typically may not have all of the resources required for complex new product development [21]. A vast number of valuable new ideas often never take off due to lack of resources and time [22]. The proposed model in this paper conveys the mutual benefits of OI between universities and the food industry and offers a successful framework structure of the operation. The framework is versatile, allows for scheduled review meetings during 


\section{Dimitris Skalkos \\ Advanced Food Products Prepared through Academic and Industry Collaboration}

development, and displays milestones visually. This collaborative program brings the food sector into close contact with the university community. This partnership is not well developed in many countries, despite being considered critical by many experts for the development of an innovation ecosystem. Industry and universities must work together to contribute to global and humanitarian development, and solve problems that are the urgent need to society and have a global impact [22]. As the number of such partnerships increases over time, there can be more sharing of resources and knowledge across partners around the world. On a number of occasions a solution or idea in one industry can spark a new application in another industry [23]. In the future, we will see more such collaborations due to the advantages they bring, resulting in innovation ecosystems. More and more insulated organizations should transform into open systems with joint teams and innovative people. New forms of innovation partnerships sharing may emerge in the future as more OIs take place. Why reinvent the wheel when one can access knowledge anywhere in the world rapidly through modern communication technologies, and speed up their own product development via open Innovation?

\section{References}

- Bommer, M., Jalajas, D.S., 2002. The innovation work environment of high-tech SMEs in the USA and Canada. R\&D Management, England 32 (5), 379-386. Crossref

- Clark, K.B., Wheelwright, S.C., 1993. Managing New Product and Process Development, first ed. Free Press, New York, 911pp.

- Otto, K., Wood, K., 2001. Product Design: Techniques in Reverse Engineering and New Product Development, seventh ed. Prentice-Hall, NJ.

- Ulrich, K.T., Eppinger, S.D., 2004. Product Design and Development, third ed. McGraw-Hill Irwin, USA.

- Clark, K.B., Wheelwright, S.C., 1993. Managing New Product and Process Development, first ed. Free Press, New York, 911pp.

- Kaminski, P.C., 2000. Desenvolvendo produtos com planejamento, criatividade e qualidade, first ed. Livros Te 'cnicos e Cientı ' ficos Editora, Rio de Janeiro, 146pp.

- Adler, Paul S. \& Kwon, Seok Woo 2002 Social capital: Prospects for a new concept Academy of Management Review January pp 17-48 Crossref

- Baldwin, J.R., 2000. Innovation and Training in New Firms. Statistics Canada, Ottawa.

- Santoro, Michael D. and Chakrabarti, Alok K. 2001 Corporate strategic objectives for establishing relationships with university research centers IEEE Transactions on Engineering Management Vol. 48 No. 2 May pp 157-163 Crossref

- Saguy I.S. 2011. Academia and Food Industry Paradigm Shifts Required for Meeting Innovation Challenges. Trends in Food Science \& Technology. Crossref

- Chesbrough H.W. 2003. Open Innovation: the New Imperative for Creating and Profiting from Technology. Harvard Business School Press, Boston, MA, USA.

- Gassmann O., Enkel E. \& Chesbrough H. 2010. The Future of Open Innovation. R\&D Management, 40(3), 213-221. Crossref

- Lafley A.G. \& Charan R. 2008. The Game Changer. Crown Business, New York, NY, USA.

- Traitler H., Watzke H.J. \& Saguy I.S. 2011. Reinventing R\&D in an Open Innovation Ecosystem. Journal of Food Science 76 (2), R62-R68.

- van de Vrande V., de Jong J.P.J., Vanhaverbeke W. \& de Rochemont M. 2009. Open Innovation in SMEs: Trends, Motives and Management Challenges. Technovation, 29(6-7), 423-437. Crossref

- Bianchi M., Campodall'Orto S., Frattini F., \& Vercesi P. 2010. Enabling Open Innovation in Small- and Medium-sized Enterprises: How to Find Alternative Applications for Your Technologies. R\&D Management, 40(4), 414-431.

- Raymond L. \& St-Pierre J. 2010. R\&D as a Determinant of Innovation in Manufacturing SMEs: An Attempt at Empirical Clarification. Technovation, 30(1), 48-56. Crossref

- Tyler J.E.III. 2009. Advancing University Innovation: More Must Be Expected-More Must Be Done. Minnesota Journal of Law, Science \& Technology, 10(1), 143-212.

- Hagel J.I. III, Brown J.S. \& Davison L. 2010. The Power of Pull. How Small Moves, Smartly Made, Can Set Big Things in Motion. Basic Books, New York, NY, USA. 


\section{Dimitris Skalkos}

Advanced Food Products Prepared through Academic and Industry Collaboration

- Markham S.K., Ward S.J., Aiman-Smith L. \& Kingon A.I. 2010. The Valley of Death as Context for Role Theory in Product Innovation. Journal of Product Innovation Management, 27(3), 402-417. Crossref

- Lim, S. S., E. L. Loo, and A. Shekar, 2001, Product development partnership programme and its evaluation. In R. A.Dwight, and E. J.Colville (Eds.), The 8th Australasian Conference of Engineering Management Educators (pp. 129-137).

- Chesbrough, H. W., 2006, Open Business Models: How to Thrive in the New Innovation Landscape. Cambridge MA: Harvard Business School Publishing.

- Griffin, A., R. Price, and B. Vojak, 2012, Serial Innovators: How Individuals Create and Deliver Breakthrough Innovations in Mature Firms, Stanford University Press. Crossref 